\title{
Experimental evaluation of pumpjet propulsor for an axisymmetric body in wind tunnel
}

\author{
Ch. Suryanarayana ${ }^{1}$, B. Satyanarayana ${ }^{2}$, K. Ramji ${ }^{3}$ and A. Saiju ${ }^{1}$ \\ ${ }^{I}$ Naval Science and Technological Laboratory, Visakhapatnam, India \\ ${ }^{2}$ Andhra University, Visakhapatnam, India \\ ${ }^{3}$ Department of Mechanical Engineering, AU College of Engineering, Visakhapatnam, India
}

\begin{abstract}
Design of a Pump Jet Propulsor (PJP) was undertaken for an underwater body with axisymmetric configuration using axial flow compressor design techniques supported by Computational Fluid Dynamics (CFD) analysis for performance prediction. Experimental evaluation of the PJP was carried out through experiments in a Wind Tunnel Facility (WTF) using momentum defect principle for propulsive performance prior to proceeding with extensive experimental evaluation in towing tank and cavitation tunnel. Experiments were particularly conducted with respect to Self Propulsion Point (SPP), residual torque and thrust characteristics over a range of vehicle advance ratio in order to ascertain whether sufficient thrust is developed at the design condition with least possible imbalance torque left out due to residual swirl in the slip stream. Pumpjet and body models were developed for the propulsion tests using Aluminum alloy forged material. Tests were conducted from 0 $\mathrm{m} / \mathrm{s}$ to $30 \mathrm{~m} / \mathrm{s}$ at four rotational speeds of the PJP. SPP was determined confirming the thrust development capability of PJP. Estimation of residual torque was carried out at SPP corresponding to speeds of 15,20 and $25 \mathrm{~m} / \mathrm{s}$ to examine the effectiveness of the stator. Estimation of thrust and residual torque was also carried out at wind speeds 0 and $6 \mathrm{~m} / \mathrm{s}$ for PJP RPMs corresponding to self propulsion tests to study the propulsion characteristics during the launch of the vehicle in water where advance ratios are close to Zero. These results are essential to assess the thrust performance at very low advance ratios to accelerate the body and to control the body during initial stages. This technique has turned out to be very useful and economical method for quick assessment of overall performance of the propulsor and generation of exhaustive fluid dynamic data to validate CFD techniques employed.
\end{abstract}

KEY WORDS: Pumpjet; Wind tunnel; Propulsion; Experimental techniques; Hydrodynamics.

\section{NOTATION}

$\rho \quad=$ Density of air in $\mathrm{Kg} / \mathrm{m}^{3}$

$n \quad=$ RPS of rotor (model)

$D \quad=$ Diameter of the rotor (model), $m$

$K_{T m} \quad=$ Propeller model thrust coefficient

$z \quad=$ No. of propeller blades

$J \quad=$ Advance coefficient

$n \quad=$ Revolutions of propeller per second

$A_{e} \quad=$ Expanded area of propeller

$A_{0} \quad=$ Overall area of the blade

$v \quad=$ Kinematic viscosity of air, $\mathrm{m}^{2} / \mathrm{s}$

$V_{a} \quad=$ Axial velocity, $\mathrm{m} / \mathrm{s}$

$V_{t} \quad=$ Tangential velocity, $\mathrm{m} / \mathrm{s}$

$r \quad=$ Local radius, $m$

$u \quad=$ Local velocity, $\mathrm{m} / \mathrm{s}$

$U \quad=$ Free stream velocity, $\mathrm{m} / \mathrm{s}$

Corresponding author: Ch. Suryanarayana

e-mail: surya_narayana_ch@yahoo.co.in
$C_{D} \quad=$ Coefficient of drag

$d \quad=$ Body diameter

$K_{Q} \quad=$ Torque coefficient

$C_{T} \quad=$ Thrust coefficient

$K_{T F} \quad=$ Thrust coefficient

$C_{r t} \quad=$ Coefficient of residual thrust

$R_{n f} \quad=$ Propeller Reynolds number at full scale

$R_{n p m}=$ Propeller Reynolds number at model scale

$C_{t f} \quad=$ Residual thrust coefficient

\section{INTRODUCTION}

Conventionally towing tank and cavitation tunnels are used for experimental validation of the hull form and propulsor designs for underwater naval platforms. Experimental techniques at these facilities are well established and being used for a long time. Though the predictions made at these facilities are fairly accurate, they 
are expensive, time-consuming and require large scale test set-ups. On the other hand, wind tunnel experiments are considerably economical and quick. In addition, very detailed fluid flow information and data can be generated which is essential for validation of computational codes and techniques. This data is very useful in detailed assessment of the performance of the vehicle and its propulsor and helps in understanding the reasons behind the success or failure of the design.

The concept of pumpjet originated from naval architecture discipline quite early, but many mechanical engineers have contributed for development of the pumpjet technology. A brief account of the evolution of the pumpjet knowhow/ technology is detailed in the following paragraphs. Wislicenus (1960) reported that primary requirements of propellers viz., low machinery weight, good efficiency and good cavitation resistance are conflicting requirements. Thurston and Ansler (1966) \& Thurston and Evanbar (1965) reported that jet efficiency values of well over $100 \%$ are attainable and as a result, values of propulsive efficiency approaching $100 \%$ are attainable. A method for pumpjet design was published by Henderson et al. (1964) and they brought out various issues associated with the design and used improved NACA cascade data but not included the influence of cowl on the performance. Thurston and Ansler (1966) revived the status of marine propellers and presented general operating regimes of the propellers. Vosper and Brown (1996) reported that UK fitted their submarines with pumpjets. It was also reported that American Sea-wolf submarine was to be fitted with pumpjet. McCormik et al. (1956) studied the designs of contrarotating propellers and pumpjets with reference to their efficiency and cavitation. Markatos (1984) carried out computational investigations of thick axi-symmetric turbulent boundary layer and wakes of bodies of revolution. McCormick et al. (1956) have published a comprehensive report on torpedo propellers including the manufacturing requirements. Turbo-machinery principles, theory and design calculations were published in a book by Wislicenus(1947). Stefan Ivanell (2001) carried out a detailed CFD simulation of flow over torpedo and pumpjet jointly with SAAB Bofors Underwater Systems.

Mean while considerable work has been undertaken at NSTL, Visakhapatnam. Suryanarayana (1999) developed a pumpjet for torpedo and details were reported in an internal report. Das et al. (2006) carried out CFD simulation of PJP using RANS through finite volume formulation using $k-\varepsilon$ model and predicted the performance reasonably well comparable with experimental results. A modern cavitation tunnel facility was setup at NSTL with a test section size of $1 m \times 1 m \times 6 m$ exclusively for the development of naval vessels and their propellers. Suryanarayana (2004) presented a paper during National Science Day Celebrations on technological challenges encountered at NSTL in the development of advanced propellers for high speed marine vehicles. Further Suryanarayana (2003) reported on the innovative techniques employed at NSTL for manufacture of propellers using computer aided machining (CAM). Suryanarayana et al. (2006a) reported the development of hydrodynamic profile and propellers for a decoy required to hover over a depth range and experimental technique employed for evaluation of performance using an instrumented decoy. Suryanarayana et al. (2006b) published a performance evaluation technique for pumpjet through model testing in cavitation tunnel.

A low speed wind tunnel (Fig. 1) with a maximum speed of $60 \mathrm{~m} / \mathrm{s}$, has been built for the development of propulsors for underwater application, and to validate the CFD techniques employed for underwater vehicle designs. The Wind Tunnel has been fully automated and equipped with essential instrumentation to measure pressure profile on bodies, characterize the flow all over the body and propulsor, and measurement of forces and moments. It is being equipped with Particle Imaging Velocimetry (PIV) system which will be operational in about a year. Design know-how of the pumpjet is a closely guarded secret and not available freely in the open literature. As part of the development of this technology at Naval Science \& Technological Laboratory, Visakhapatnam, a pumpjet has been designed for a Light Weight Body (LWB) using axial compressor theory and associated cascade data. Propulsive performance was estimated using CFD analysis in FLUENT.

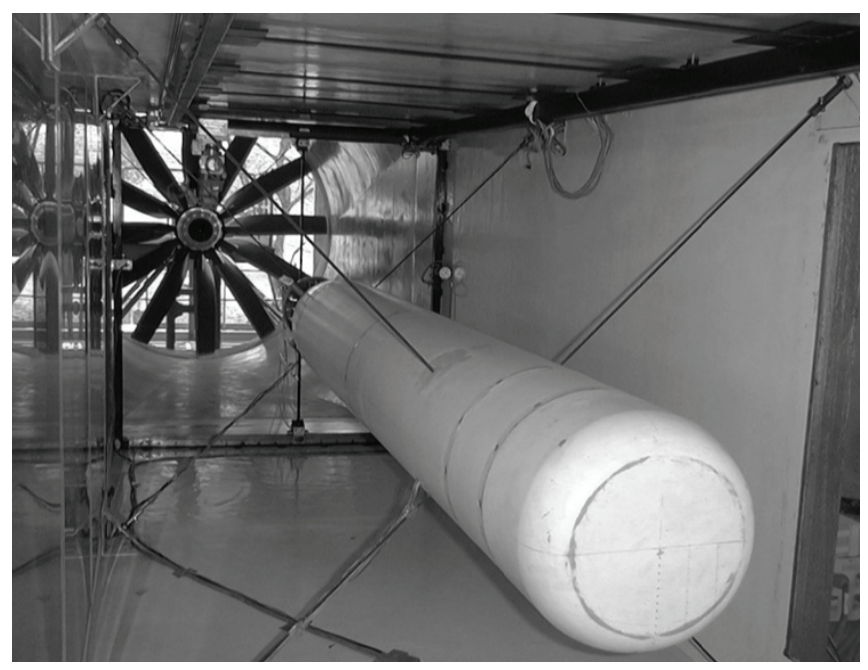

Fig. 1 LWB Model aligned in the test section at zero incidence angle.

Full scale Aluminum models of the body and PJP were developed for tests in wind tunnel to estimate self propulsion point, residual imbalance torque, thrust characteristics over a range of advance ratios, $J=0$ to 3.5 . Experiments were conducted over speed range of $15 \mathrm{~m} / \mathrm{s}$. to $30 \mathrm{~m} / \mathrm{s}$. to vary, $J=$ 2.74 to 1.86 for estimation of self propulsion point. Swirl measurements in the slip stream were undertaken using a 5 hole probe at self propulsion points. Bare body drag was estimated over wind speeds of $2.5 \mathrm{~m} / \mathrm{s}$ to $25 \mathrm{~m} / \mathrm{s}$. Results have been analyzed and found that the predictions were very close to the design estimation and the data obtained from CFD analysis. This experimental work established an accurate technique to validate the design of PJP for self propulsion point, residual swirl and thrust characteristics. The details of the experimental set up, techniques/tools employed, and results obtained are presented in this paper. 


\section{SCOPE OF THE EXPERIMENT}

The main objectives of the experiment are to estimate self propulsion point, residual torque and thrust characteristics of the body fitted with PJP. The test conditions in which the tests were conducted are listed in the following test matrices for the respective investigations.

- Self propulsion point

The following tests were conducted as per the program at Table 1 for estimation of self propulsion point.

Table 1 Test matrix for estimation of self propulsion point of the PJP.

\begin{tabular}{|c|c|c|c|c|c|}
\hline $\begin{array}{c}\text { Wind } \\
\text { Speed }(\mathrm{m} / \mathrm{s})\end{array}$ & $\begin{array}{c}\text { Advance } \\
\text { coefficient } \\
J=2.74\end{array}$ & $J=2.37$ & $J=2.17$ & $J=2.05$ & $J=1.86$ \\
\hline 15 & $\sqrt{ }$ & $\sqrt{ }$ & $\sqrt{ }$ & $\sqrt{ }$ & $\sqrt{ }$ \\
\hline 20 & $\sqrt{ }$ & $\sqrt{ }$ & $\sqrt{ }$ & $\sqrt{ }$ & $\sqrt{ }$ \\
\hline 25 & $\sqrt{ }$ & $\sqrt{ }$ & $\sqrt{ }$ & $\sqrt{ }$ & $\sqrt{ }$ \\
\hline 30 & $\times$ & $\times$ & 2.15 & 2.14 & $\times$ \\
\hline
\end{tabular}

- Measurement of swirl

The following tests were conducted as per the test program at Table 2 for measurement of swirl using a 5 hole probe at SPP of the corresponding wind speed.

Table 2 Test matrix for measurement of swirl.

\begin{tabular}{|c|c|c|}
\hline Wind Speed $(m / s)$ & $J$ & PJP RPM \\
\hline 0 & 0 & 2260 \\
\hline 6 & 0.724 & 2260 \\
\hline 15 & 2.09 & 1960 \\
\hline 20 & 2.13 & 2560 \\
\hline 25 & 2.15 & 3170 \\
\hline
\end{tabular}

\section{- Bare body drag}

The following tests were carried out with dummy cone (without PJP) as per test matrix at Table 3 for estimation of body drag.

Table 3 Test matrix for estimation of residual thrust.

\begin{tabular}{|l|c|c|c|c|c|}
\hline Wind Speed $(\mathrm{m} / \mathrm{s})$ & 2.5 & 5 & 10 & 17.5 & 25 \\
\hline
\end{tabular}

- Residual thrust of the PJP

The following tests were conducted as per test matrix at Table 4 for estimation of residual thrust.
Table 4 Test matrix for estimation of residual thrust.

\begin{tabular}{|c|c|c|c|c|}
\hline $\begin{array}{c}\text { Wind } \\
\text { Speed }\end{array}$ & $\begin{array}{c}\text { PJP RPM - } \\
1960\end{array}$ & $\begin{array}{c}\text { PJP RPM - } \\
2260\end{array}$ & $\begin{array}{c}\text { PJP RPM - } \\
2560\end{array}$ & $\begin{array}{c}\text { PJP RPM - } \\
3170\end{array}$ \\
\hline $\begin{array}{c}0 \sim 25 \\
\text { in steps } \\
\text { of } 2.5 \mathrm{~m} / \mathrm{s}\end{array}$ & $\sqrt{ }$ & $\begin{array}{c}\text { Only at } \\
17.5 \mathrm{~m} / \mathrm{s}\end{array}$ & $\sqrt{ }$ & $\begin{array}{c}0 \text { to } \\
27.5 \mathrm{~m} / \mathrm{s}\end{array}$ \\
\hline
\end{tabular}

\section{EXPERIMENTAL SETUP}

The tests were carried out at $0^{\circ}$ of incidence with a full scale LWB model made of aluminum fitted with fins and PJP.

\section{NSTL wind tunnel}

NSTL Wind tunnel is a low speed open circuit wind tunnel. The salient features of the tunnel are as below:

\begin{tabular}{|l|l|}
\hline Test section: & $1.5 \times 1.5 \times 4.0 \mathrm{~m}$ \\
\hline Plenum chamber: & $4.3 \times 4.3 \times 4.0 \mathrm{~m}$ \\
\hline Contraction: & $\begin{array}{l}\text { section varying from } 4.3 \times 4.3 \mathrm{~m} \\
\text { square to } 1.5 \times 1.5 \mathrm{~m} \text { test section }\end{array}$ \\
\hline Diffuser: & $\begin{array}{l}\text { section varying from } 1.5 \times 1.5 \mathrm{~m} \\
\text { square to } 3.048 \mathrm{~m} \text { dia. circle }\end{array}$ \\
\hline DC motor: & $25 \mathrm{KW}, 750 \mathrm{rpm}$ max \\
\hline Tunnel fan: & $\begin{array}{l}12 \mathrm{bladed} \text { CFRP fan } \\
\text { with diameter } 3.04 \mathrm{~m}\end{array}$ \\
\hline $\begin{array}{l}\text { Maximum speed } \\
\text { at test section: }\end{array}$ & $55 \mathrm{~m} / \mathrm{s}$ \\
\hline
\end{tabular}

The following measurements are carried out in the tunnel:

- Pressure distribution over the body and control surfaces using multi port electronic pressure sensors (EPS).

- Detailed explorations of velocity at boundary layer and wake using single wire, cross wire, 5 hole probe and other Pitot probes.

- Shear stress measurement with shear stress sensors (Mc Crosky gauges).

- Measurement of forces and moments on body and appendages with dynamometers.

- Detailed study of flow patterns using flow visualisation techniques. 


\section{Model details}

Details of the model is provided at Fig. 2, Fig. 3a and Table 5.

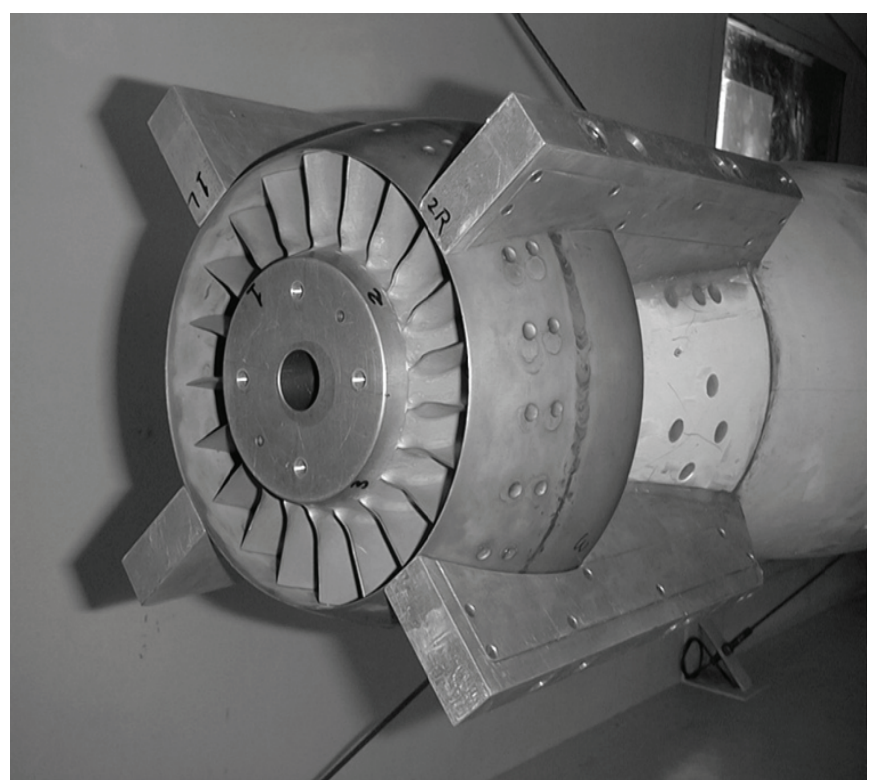

Fig. 2 LWB model fitted with PJP.

Table 5 Details of the model and PJP.

\begin{tabular}{|c|c|}
\hline Model Scale & $1: 1$ \\
\hline PJP Scale & $1: 1$ \\
\hline Model length & $2920 \mathrm{~mm}$ \\
\hline Model diameter & $324 \mathrm{~mm}$ \\
\hline No. of PJP rotor blades & 15 \\
\hline PJP Rotor diameter & $220 \mathrm{~mm}$ \\
\hline No. of PJP stator blades & 21 \\
\hline PJP Cowl inlet diameter & $237 \mathrm{~mm}$ \\
\hline PJP Cowl outlet diameter & $194 \mathrm{~mm}$ \\
\hline
\end{tabular}

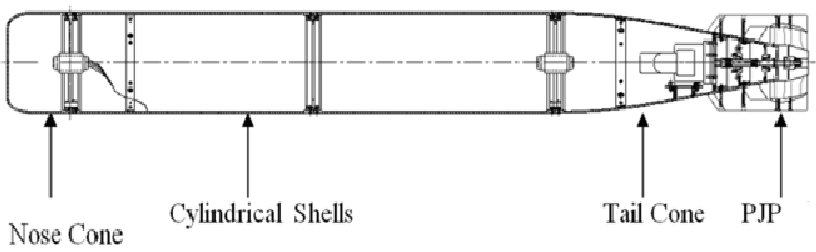

Fig. 3a Schematic diagram of LWB model fitted with PJP.
- The model has a nose cone shell, three cylindrical shells and a tail cone shell. Inner side of the shells was provided with annular rings for rigidity. The shells have provision to hold the pressure sensors.

- The tail cone has the provision to secure the motor and the PJP assembly. It has an opening cover to check the assembly, alignment of the RPM sensor unit without disturbing the model assembly.

The tests were carried out in the $1.5 m \times 1.5 m$ test section of the wind tunnel. The model was tested at Reynolds numbers of about 0.46 to 4.62 million. The blockage is about $3.66 \%$ at $0^{\circ}$ of incidence of the model.

\section{Model instrumentation \& test setup}

Schematic diagram of the tunnel instrumentation and test setup along with body model and PJP is given at Fig. 3 b.

\section{PJP and tachometer alignment}

The motor was secured in the model with a plate attached to it, which was further connected to the model with bolts and nuts. Motion is transmitted from the motor to the rotor with the help of a flexible coupling and the stator is supported on the bearing and is fixed in the cowl. Four orthogonally fitted fins hold the PJP cowl and maintain $1 \mathrm{~mm}$ clearance between rotor and cowl. An optical tachometer was fitted rigidly in the tail unit to measure rpm of the PJP rotor. The output cables of the motor and tachometer were connected to control drive.

\section{Traverse gear}

The traverse gear with a rectangular frame $(1490 \mathrm{~mm} \times 1445 \mathrm{~mm})$ was installed in the test section. A calibrated 5 hole probe was placed at the probe holder of the traverse gear and the probe ends were connected to 5 differential pressure transducers. The movement of the probe i.e., horizontal movement of the $\mathrm{Y}$ guide and vertical movement of the holding bracket of traverse gear was controlled through the stepper motors of $\mathrm{X}$ and $\mathrm{Y}$ respectively. The stepper motors were driven through the traverse controller. The traverse mechanism has a minimum step size of $0.25 \mathrm{~mm}$ and $0.5 \mathrm{~mm}$ in the vertical and horizontal direction respectively. The stepper motor rotation was controlled through a sequence of pulses fed through a DIO card, connected to data acquisition system (DAS).

\section{Control \& data acquisition}

A PC based data acquisition system (DAS) was used to acquire the experimental data from different sensors to control the tunnel fan and to traverse the probe to the desired location. The DAS consists of the following cards intended for purpose against each mentioned. LabVIEW software was used to communicate with different data acquisition cards (DACs) and sensors to acquire the data and processing the same. The DAC details are given in Table 6. 


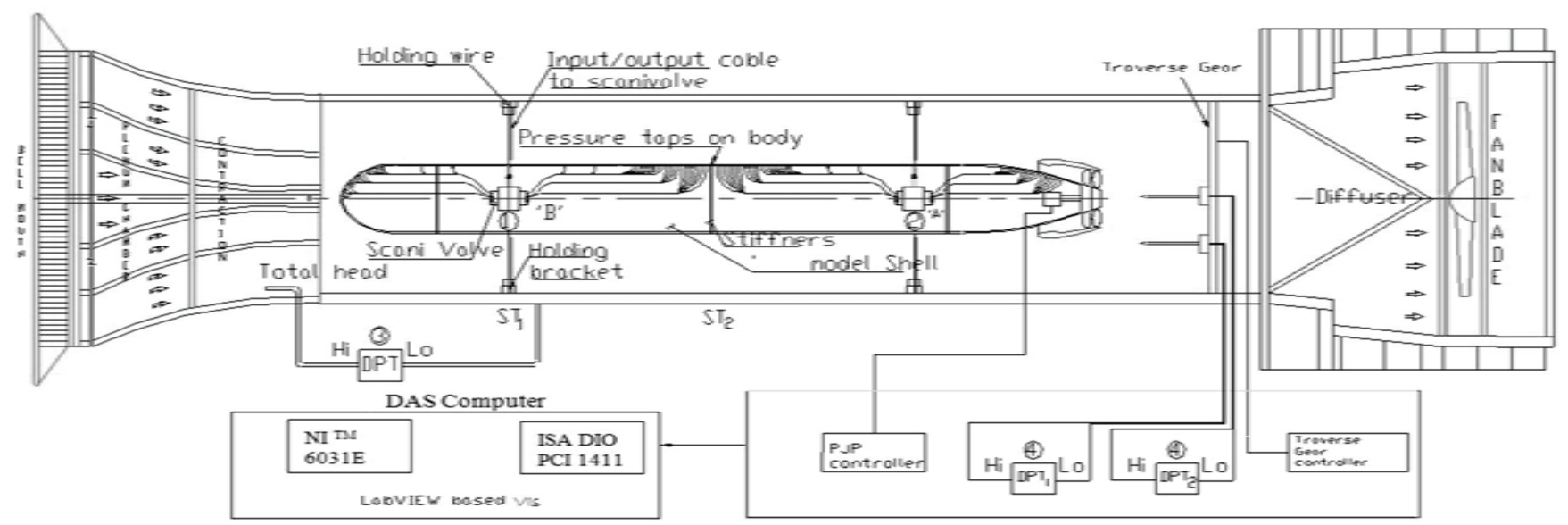

Fig. 3b Schematic diagram for instrumentation and test set up for LWB model fitted with PJP.

Table 6 details of data acquisition cards details.

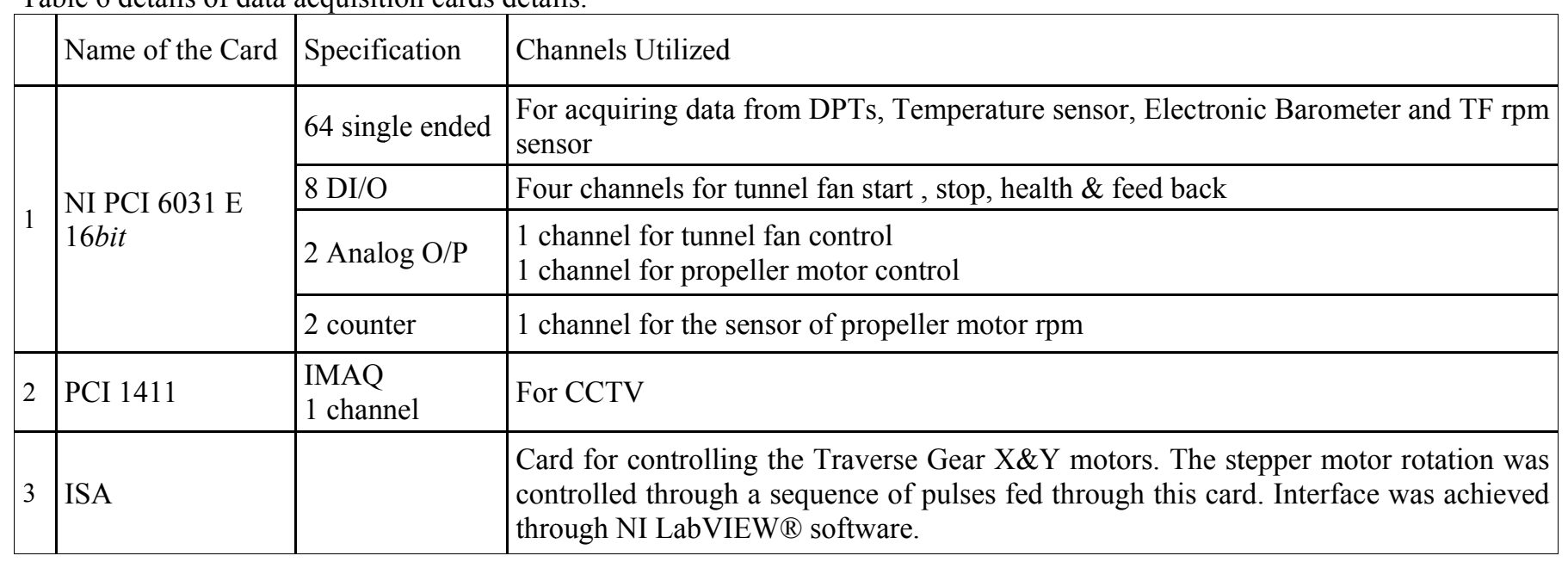

The configuration file of the DAS was programmed as per the requirement of the test. It includes the details of the model, number of pressure sensors used, channel configuration of the DACs, desired sampling rate for acquiring the data and the automatic mode of Traverse Gear control. A sampling rate of 1000 was used for this experiment. A text file containing the coordinates of the probe position was fed to configure the front panel to move the Traverse Gear automatically. The DC stepper motors were controlled from the DAS to carry out the $\mathrm{X}$ and $\mathrm{Y}$ motions of the probe with step sizes of $0.5 \mathrm{~mm}$ and $0.25 \mathrm{~mm}$ respectively. The fan blades, fan RPM indicator on drive panel and stepwise movements of the traverse gear can be observed through four in number closed circuit television cameras.

The ambient temperature, pressure, the wind velocity at different positions along the tunnel and at the probes, tunnel fan RPM, the position of the probe etc., are displayed and saved automatically by the DAS. A screen shot of the DAS screen is given below. Front panels were developed in NI LabVIEW.

\section{TEST METHOD AND DATA ANALYSIS}

\section{Measurement of axial velocity component in wake}

Wake survey for the axial velocity profile was carried out using a Pitot static probe, mounted on a 2D traverse gear holder. The Pitot static probe was placed at a distance of 310 $\mathrm{mm}$ from the body end point, such that the probe is not in the region of flow separation. The probe was moved from the free stream to the body center and then again to the free stream in the radial direction. The traverse gear movement was controlled from the Data Acquisition System and the probe was held at each investigation point for a duration of 4 sec to acquire the pressure at that instance. Another Pitot static probe was fixed to the traverse gear guide to get the free stream pressure during the same time period. From both the Pitot static probes, the local and free stream pressures were obtained from which the wake velocity profile was estimated. Tests were conducted at tunnel speeds from $0 \sim 25$ in steps of $2.5 \mathrm{~m} / \mathrm{s}$, running the propeller corresponding to advance coefficients, as mentioned in Tables 1, 3 and 4. 


\section{Swirl measurement}

The stator primarily functions as a swirl rectifying device by eliminating the swirl created by rotor. The effectiveness of the stator was estimated by measuring the swirl in the wake using a 5 hole probe and estimating all three velocity components. The probe has 5 pressure tubes, housed in a cylindrical shell and the outputs of the tubes were connected to pressure sensors. The pressure sensed by each of the tubes was acquired and analysis was carried out for the pitch and yaw coefficients, which were used to calculate the pitch and yaw angles of the flow from the calibration curves from which the 3D velocity distribution in the wake was estimated. The test matrix for the velocity components measurement was given in Table 2 .

\section{Momentum defect principle}

Drag of the body running at speed $U \alpha$ can be estimated by measurement of decrement in momentum or momentum defect across the wake of the body as given in the equation (1) to (3).

$$
\begin{aligned}
D & =\int_{0}^{r} 2 \pi r \rho u\left(U_{\infty}-u\right) d r \\
C_{D} & =\frac{D}{\frac{1}{2} \rho U_{\infty}^{2}\left(\pi \frac{d^{2}}{4}\right)}=\int \frac{2 \pi r \rho\left(U_{\infty}-u\right) d r}{\frac{1}{2} \rho U_{\infty}^{2}\left(\pi \frac{d^{2}}{4}\right)} \\
C_{D} & =\frac{16}{d^{2}} \int r\left(\frac{u}{U_{\infty}}\right)\left(1-\frac{u}{U_{\infty}}\right) d r
\end{aligned}
$$

Where

$$
\frac{u}{U_{\infty}}=\sqrt{\frac{P_{0}\left(\text { local }-P_{a}\right)}{P_{0}(\text { mainstream })-P_{a}}}
$$

\section{Estimation of self propulsion point}

The self propulsion point at a wind speed is the advance coefficient at which the thrust becomes equal to the drag, i.e., the coefficient of residual thrust, estimated by the momentum defect, becomes zero. Fig. 4 shows the test setup used for measurement of the momentum defect. In order to determine the SPP, the fan drive system was operated at different rpm to achieve different model Reynolds numbers of 0.462 to 4.62 million and PJP was operated at different RPM to achieve desired advance coefficients. The total pressure and static pressure in the wake at $220 \mathrm{~mm}$ downstream was measured by traversing the Pitot-static probe at different radii from the center of the model, radially outwards. Velocity profile was obtained at different propulsor advance coefficients and the time rate of change of momentum was estimated to obtain residual drag/thrust. The residual drag/thrust was nondimensionalised w.r.t. dynamic head and midship area. The coefficient of residual thrust $\left(C_{r t}\right)$ is plotted against the advance coefficient to obtain the advance coefficient at which the $C_{r t}$ becomes zero i.e., the self-propulsion point $J$.

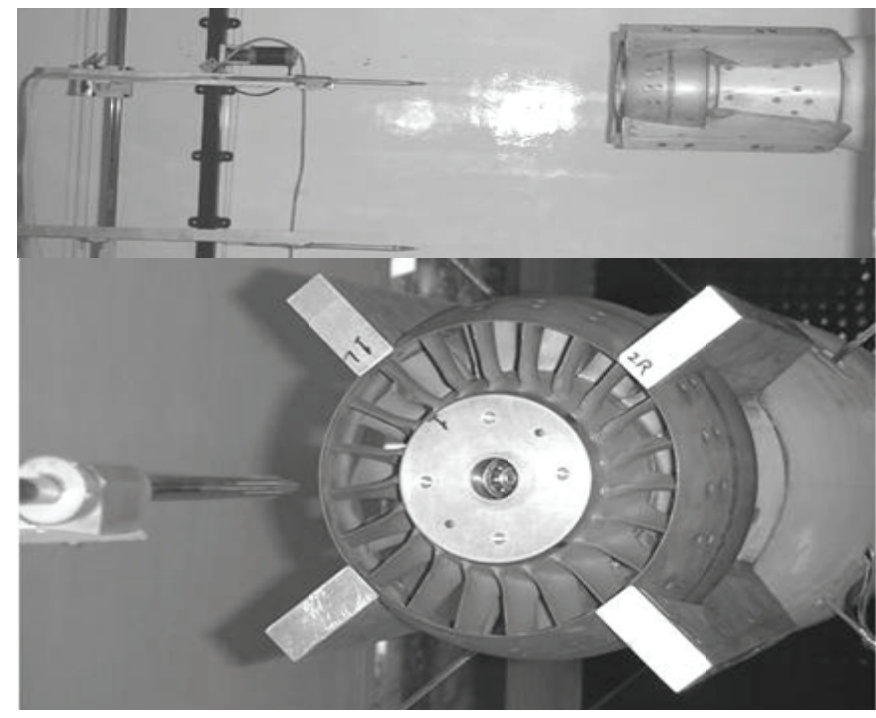

Fig. 4 Test setup for the wake survey of LWB body model fitted with PJP.

\section{Estimation of bare body drag}

For estimating the thrust delivered by the propulsor, the bare body drag was estimated at different wind speeds. The model was fitted with a dummy hub at the tail cone, and the wake in the downstream was measured using the Pitot-static probe. The drag was estimated for the speeds given in the test matrix Table 3.

\section{Estimation of residual thrust of PJP}

For the estimation of the residual thrust, wake survey was carried out while rotor was operated at self propulsion point corresponding the wind speed of 15,20 and $25 \mathrm{~m} / \mathrm{s}$ respectively. The test matrix is given in Table 4. From the momentum defect, the residual thrust was estimated and was added to the bare body drag, for estimating the resultant thrust developed by the propeller.

\section{Extrapolation of thrust for body in sea water}

The thrust developed in the air was nondimensionalized as $K_{T m}$ and was scaled to Reynolds number corresponding to hydrodynamic regime using ITTC 1978 prediction method.

Thrust coefficient for the model, $K_{T m}$

$K_{T m}=$ Thrust $/\left(\rho n^{2} D^{4}\right)$

The relations for the extrapolation, corrected by ITTC are given below.

$$
\begin{aligned}
K_{t f}= & K_{T m}+ \\
& \frac{0.00145+0.0045 \ln \left(C_{T}+1\right)}{1.8} \cdot\left(\log R n_{p f}-\log R n_{p m}\right) \\
C_{T}= & \frac{8}{\pi} \cdot \frac{K_{T}}{J^{2}} \\
R n_{p f}= & \frac{5 \cdot n \cdot D^{2}}{\rho \cdot z} \cdot \frac{A_{e}}{A_{0}}
\end{aligned}
$$




\section{Estimation of imbalanced torque of PJP}

If the flow coming out of the propeller has any swirl, it will induce an imbalanced torque to the body and it causes the body to deviate from the target. For estimating the imbalanced torque, 5 hole probe was used and probing was carried out in the axisymmetric mode to get the velocity components. The tests were carried out at the corresponding self propulsion points of the wind speeds. Formulation for residual torque estimation for axisymmetric flow is given below.

Residual Torque $=2 \pi \int_{0}^{r} \rho \cdot r^{2} V a . V t . d r$ in $\mathrm{Nm}$

The estimated imbalanced torque was non dimensionalised as $K_{q}$ the same was used for extrapolating the results to the full scale conditions.

$K_{q}=$ Residual torque $/ \rho n^{2} D^{5}$

\section{RESULTS \& DISCUSSIONS}

Measurements made behind the body both with and without pumpjet are presented along with associated estimates of vehicle performance in the following paragraphs in the respective sections.

\section{Results}

Axial velocity profile in wake

Axial velocity in wake is shown in Fig. 5 below. The velocity profile is symmetric about the model axis indicating proper model alignment. The plot shows consistent wake profiles and systematic variations for change in rotor RPM.

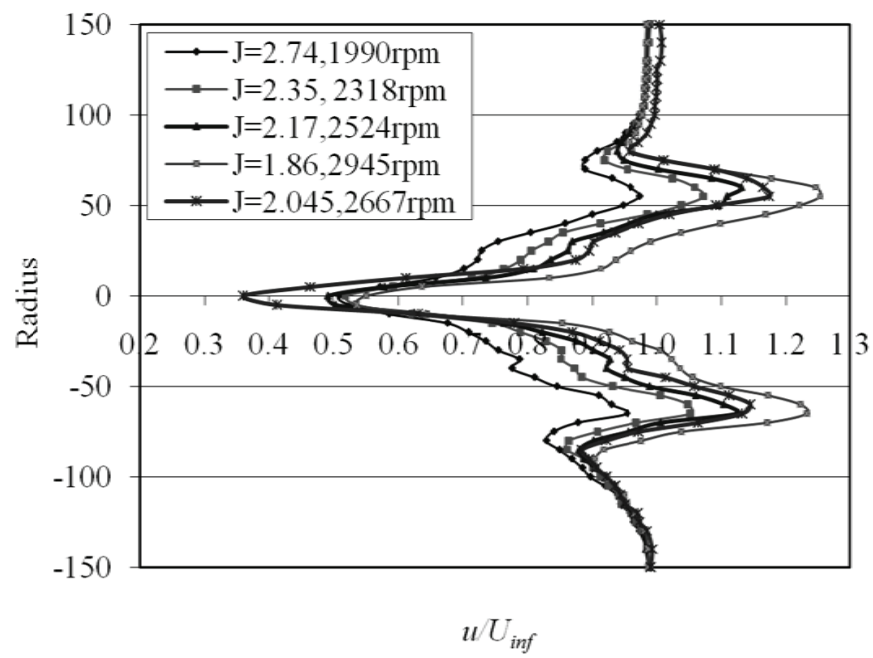

Fig. 5 Axial velocity profile at different radii from the centre of the model.

Tangential velocity profile in wake

The profile of the tangential velocity at different radii from the center of the body is shown in Fig. 6 and 7 below.

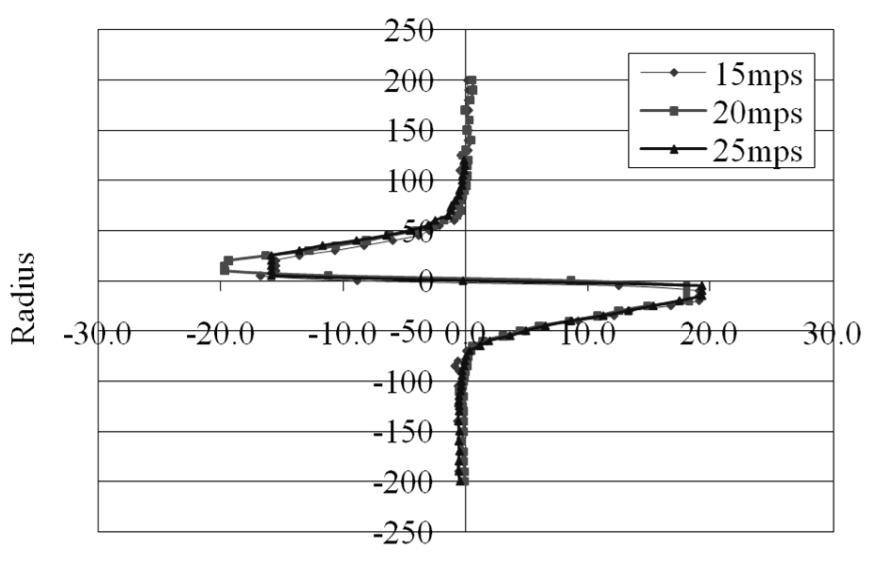

Yaw Angle

Fig. 6 Swirl of the flow at different radii from the centre of the model.

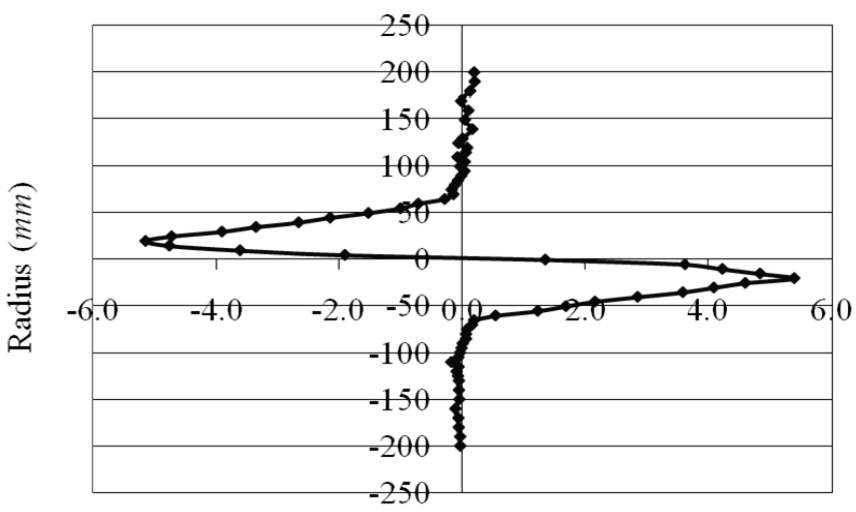

Tangential veloctiy $(\mathrm{m} / \mathrm{s})$

Fig. 7 Tangential velocity profile at different radii from the centre of the model.

From the above graphs, it can be observed that the tangential velocity in the wake at the blade area (radius $70 \mathrm{~mm}$ to $110 \mathrm{~mm}$ ) is very low (yaw angle of the order of $0.5^{\circ}$ only) but higher at the hub zone.

\section{Self propulsion point}

Coefficient of residual Thrust $\left(C_{r t}\right)$ at different propeller rpm for three wind speeds are plotted against advance coefficients to obtain the self-propulsion point. From the Fig. 8 , it can be observed that, the self propulsion point collapses at $J=2.15$ as the wind speed increases.

Table 7 Self Propulsion RPMs corresponding to Different Wind Speeds.

\begin{tabular}{|c|c|c|}
\hline Wind Speed & SPP - J & PJP RPM \\
\hline 15 & 2.09 & 1960 \\
\hline 20 & 2.13 & 2560 \\
\hline 25 & 2.15 & 3170 \\
\hline
\end{tabular}




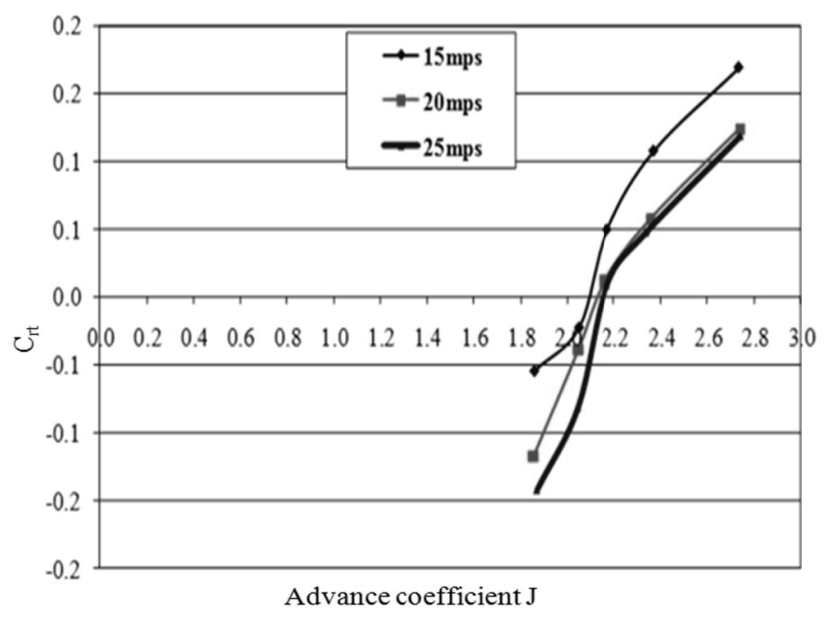

Fig. 8 Estimation of self propulsion point.

\section{Estimation of bare body drag}

The velocity profile measured for the bare body with dummy is shown in Fig. 9 below. The defect in the momentum was calculated to get the drag of the bare body and coefficient of drag $C_{d}$ was estimated.

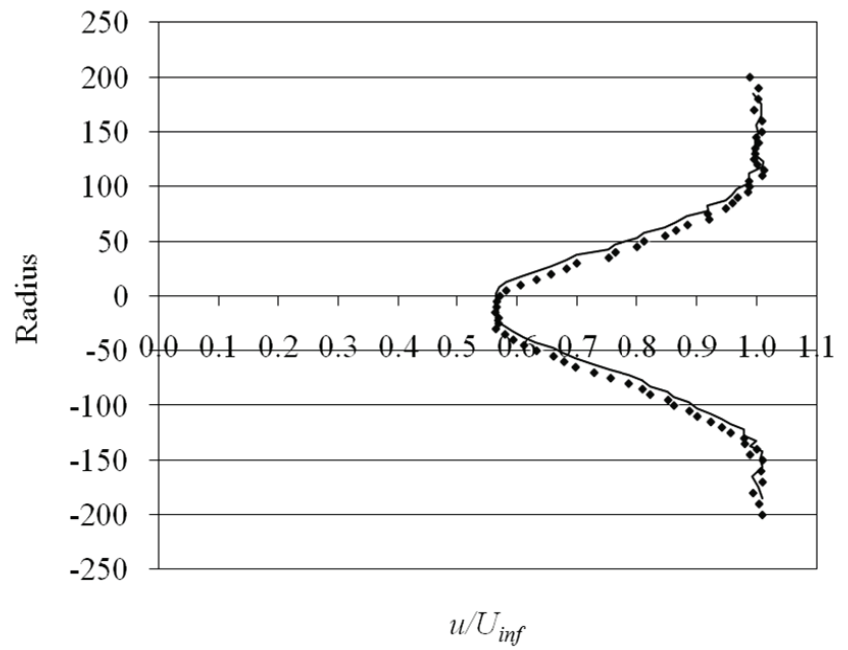

Fig. 9 Velocity profile at different radii from the centre of the bare body at tunnel $17.5 \mathrm{~m} / \mathrm{s}$.

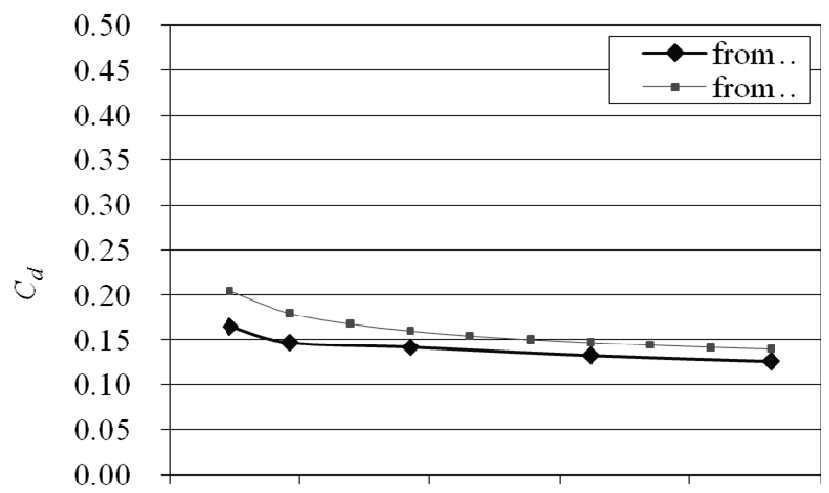

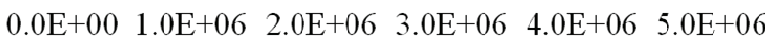

Reynolds number

Fig. $10 C_{d}$ vs $R_{n}$ for bare body with dummy hub.
Residual thrust of the PJP

The axial velocity profile in the wake at PJP RPM 2560, at tunnel speeds 0 to $25 \mathrm{~m} / \mathrm{s}$ at an interval of $2.5 \mathrm{~m} / \mathrm{s}$ is shown below.

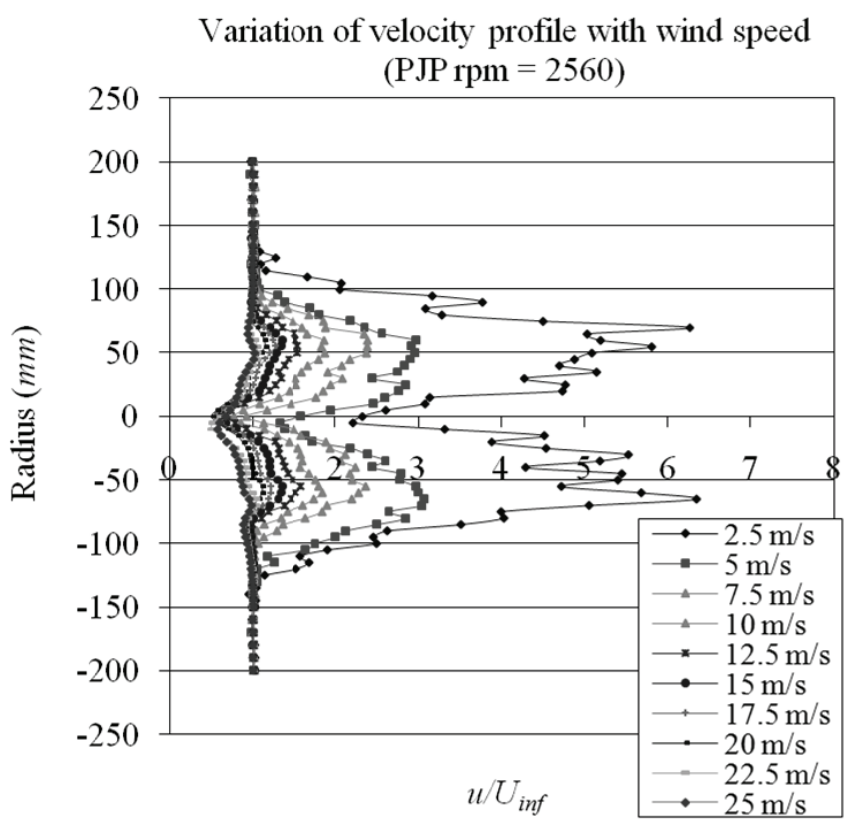

Fig. 11 Velocity profile at different advance coefficients (propeller running at constant RPM).

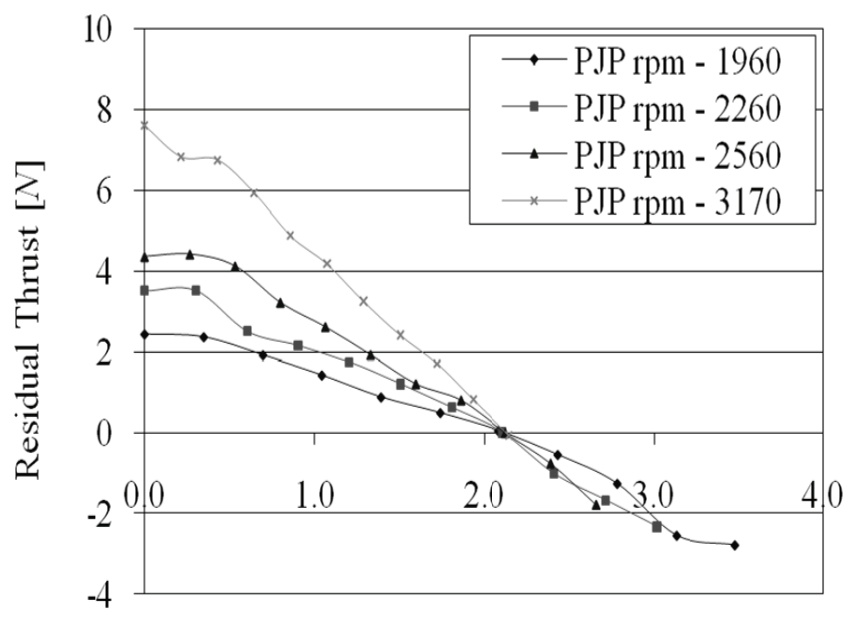

Advance Coefficient $[J]$

Fig. 12 Variation of residual thrust with advance coefficient at four different propeller RPMs.

Thrust

The thrust delivered by the PJP at Four propeller RPMs corresponding to SPP at 15, 17.5, 20 and $25 \mathrm{~m} / \mathrm{s}$ at different wind speeds are shown in Fig. 13 below. Thrust at Wind Speed $17.5 \mathrm{~m} / \mathrm{s}$, corresponding to the propeller RPM of 2200 was found to be $1808.96 \mathrm{~N}$. Thrust at bollard pull condition is given in Table 8 below. 


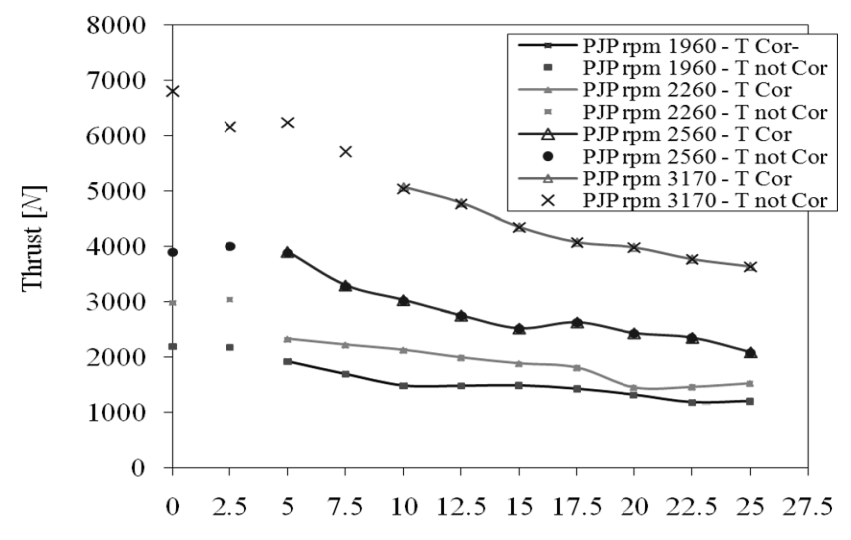

Advance Velocity $[\mathrm{m} / \mathrm{s}]$

Fig. 13 Variation of thrust with advance coefficient at four different propeller RPMs.

Table 8 Thrust delivered at 4 different PJP RPMs at bollard pull condition.

\begin{tabular}{|c|c|}
\hline PJP RPM & Thrust at bollard pull condition $(N)$ \\
\hline 1960 & 2185.29 \\
\hline 2260 & 2977.24 \\
\hline 2560 & 3899.17 \\
\hline 3170 & 6804.11 \\
\hline
\end{tabular}

\section{Imbalanced torque of PJP}

The imbalanced torque at different operating regimes is given in Table 9 below

Table 9 Imbalanced torque.

\begin{tabular}{|c|c|c|}
\hline Wind speed & PJP RPM & Imbalanced torque $\mathrm{Nm}$ \\
\hline 0 & 2260 & -2.815 \\
\hline 6 & 2260 & 4.404 \\
\hline 15 & 1960 & 10.466 \\
\hline 17.5 & 2200 & 14.426 \\
\hline 20 & 2560 & 20.291 \\
\hline 25 & 3170 & 35.941 \\
\hline
\end{tabular}

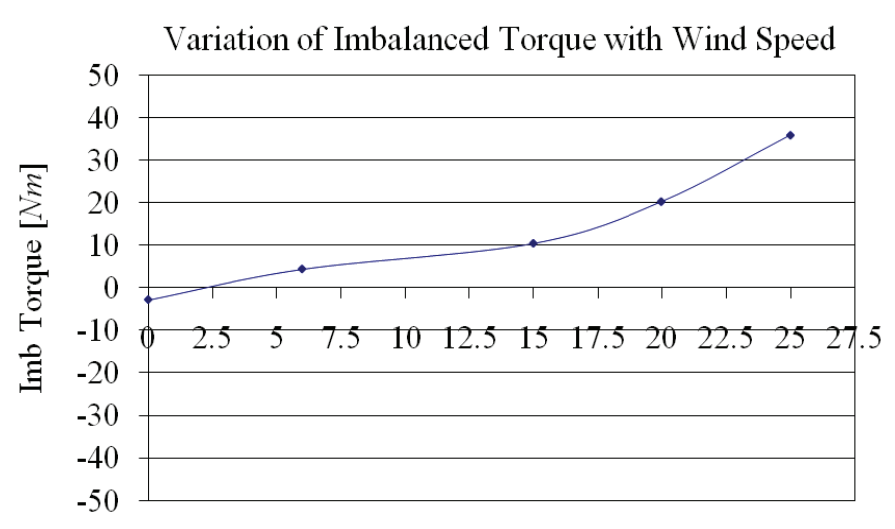

Wind Speed $[\mathrm{m} / \mathrm{s}]$

Fig. 14 Variation of imbalance torque with axial velocity.

\section{Discussions}

In order to estimate self propulsion point and propulsive performance of the vehicle, axial velocity profiles $\left(u / U_{\infty}\right)$ over a range of advance coefficient, 1.86 to 2.74 , at three free stream velocities viz., 15, 20 and $25 \mathrm{~m} / \mathrm{s}$ were obtained and data are given at Fig. 5. Coefficient of residual thrust was estimated at the above test conditions (Fig. 8) and self propulsion points were determined at the above free stream speed and presented at Table 7 and found to be converging at 2.15 and close to the design advance coefficient, 2.17.

Tangential velocity profiles were also obtained at the above free stream velocities $15,20,25 \mathrm{~m} / \mathrm{s}$ and found to collapse together as one profile indicating the flow is completely turbulent and data is presented at Fig. 6 and Fig. 7. This data is useful in estimation of residual torque that could not be eliminated by the stator.

Body drag was estimated using the velocity profiles (Fig. 9) in the wake of body with a dummy hub using momentum defect technique at equation (2) over a range of Reynolds number and compared with tow tank measurements at Fig. 10. Results are found to be closely matching and it confirms that the technique is reasonably accurate for the application.

In order to estimate propulsive performance of the vehicle over full range of advance coefficient, axial and tangential wake survey has been conducted at four propeller RPMs viz., 1960, 2260, 2560 and 3170, over full range of free stream velocity, 0 to $25 \mathrm{~m} / \mathrm{s}$. at intervals of $2.5 \mathrm{~m} / \mathrm{s}$. Axial velocity profile at RPM 2560 is given at Fig. 11.

Residual thrust is estimated over a range of advance coefficient 0 to 3.5 using the wake data and the same is provided at Fig. 12. The plot demonstrates the convergence of self propulsion point at an advance coefficient, 2.15 confirming the technique is perfected. Thrust developed by PJP at the above four RPMs over the full range of free stream velocities is presented at Fig. 13 and thrust developed at bollard pull condition is provided at Table 8. This information is essential to ensure that the propeller develops adequate initial thrust to accelerate the vehicle quickly to reach steady operational speed.

Imbalance torque has also been estimated at different operational regimes using the tangential velocity profiles obtained and provided at Table $9 \&$ Fig. 14, and found that the imbalance torque is not more than $10 \%$ of the full torque of the propulsor.

\section{CONCLUSIONS}

Following are the conclusions drawn from the investigations undertaken:

- The self propulsion advance coefficient, J, is marginally increasing with wind speed (for Rn.1 million) but is found to collapse at 2.15 after $20 \mathrm{~m} / \mathrm{s}$. SPP estimated from wind tunnel is 2.15 and it is within $1 \%$ of the design value 2.17 . This is indeed most satisfactory. 
- Thrust developed at bollard pull condition is $2977 N$ at 2200 rpm which is twice to the thrust developed at design speed of 34knots. It is considered sufficient to accelerate the vehicle to the operating speed comfortably.

- The tangential velocity component measured along rotor blade span is marginal indicating that most of the swirl rectification by the stator could be attained. Total imbalance torque is within $10 \%$ of the design torque of $134 \mathrm{Nm}$. The actual estimation of imbalance torque is required to be carried out with extended stator hub.

\section{ACKNOWLEDMENT}

This research work has been undertaken with the support of a R\&D project funded by Defense Research and Development Organization, Ministry of Defense, India. The authors express their sincere gratitude, for permitting to publish the work, to Dr. V Bhujanga Rao, Director and Shri PK Panigrahi, Head(HRW) \& Additional Director of NSTL. Further the authors also thank the entire HRW team who have directly or indirectly supported for the research work.

\section{REFERENCES}

Wislicenus, G. F., 1960. Hydrodynamics and propulsion of submerge bodies. J. Am. Rocket Soc. 30(12), pp. 1140-1148.

Thurston, S. and Ansler, R.C., 1966. Review of marine propellers and ducted propeller propulsive devices. $J$. Aircraft, 3(3). pp. 255-261.

Thunston, S. and Evanbar, M.S., 1965. Efficiency of propulsor on body of revolution including boundary layer fluid. Journal of Aircraft, 3, pp. 270-277.

Henderson R.E. McMahon J.F. and Wislicenus G.F., 1964. A method for design of pumpjets. ORL Report No. 630209-0-7, Pennsylvania State University, 15 May 1964.

Vosper P.L. and Brown A.J., 1996. Pumpjet propulsion - a British splendid achievement. J. Naval Engineering, 36(2),

McCormick, B.W. Eisenhuth, J.J. and Lynn, J.E., 1956. A Study of torpedo propellers-Part I. Ordnance Research Laboratory, Pennsylvania State University, Report NOrd. 16597-5.
Markatos, N.C., 1984. The Computation of thick axisymmetric boundary layers and wakes around bodies of revolution. Proceedings of Institution of Mechanical Engineers, 198(4), pp. 51-62.

McCormick, B.W. and Eisenhuth, J.J., 1956. A Study of torpedo propellers-Part II. Ordnance Research Laboratory, Pennsylvania State University, Report NOrd. 16597-13.

Wislicenus, G.F., 1965. Fluid mechanics of turbo-machinery. Volume I and II, Dover Publication, New York, USA.

Stefan Ivanell, 2001. Hydrodynamic simulation of a torpedo with pumpjet propulsion system. Masters thesis, Royal Institute of Technology, Stockholm, Sweden.

Suryanarayana, Ch., 1999. Design Development and Testing of Pumpjet Propulsor. NSTL Report No. NSTL/SR/136, Visakhapatnam, India.

Das, H.N. Jayakumar, P. and Saji, V.F., 2006. CFD examination of interaction of flow on high-speed submerged body with pumpjet propulsor. $5^{\text {th }}$ Int . Conference on High Performance Marine Vehicles, Australia , 8-10 November 2006.

Suryanarayana, Ch., 2004. Advanced propulsors for high speed marine vehicles. Technological challenges and developments pursued at naval science and technological laboratory, Visakhapatnam, National Science Day, NSTL, Visakhapatnam, India, 2004.

Suryanarayana, Ch., 2003. Innovative CAM techniques for propeller manufacture. $3^{r d}$ International Conference on Navy and Ship Building Nowadays (NSN2003), St Petursburg, Russia, 26-28 June 2003.

Keshi, H. Maharana, S.N. and Suryanarayana, Ch., 2002. Design philosophy of contrarotating propellers. International Conference on Ship and Ocean Technology, SHOT-2002, IIT, Kharagpur, India, December 2002.

Suryanarayana, Ch. Reddy, K.P. Mathi, S. Swamy, P.V., and Suresh R.V., 2006. Hydrodynamic design of propulsor, profile and hovering system for an expendable decoy. International Conference in Marine Hydrodynamics 2006, NSTL, Visakhapatnam, India

Suryanarayana, Ch. Roy, S.P. and Sateesh Kumar, M., 2006. Hydrodynamic performance evaluation of an underwater body by model testing in cavitation tunnel. International Conference in Marine Hydrodynamics 2006, NSTL, Visakhapatnam, India. 